\title{
Subjective Well-being, Mental Health and Concerns During the COVID-19 Pandemic: Evidence From the Global South
}

\author{
Lina Martínez ${ }^{1}$, Valeria Trofimoff ${ }^{2}$, Isabella Valencia ${ }^{3}$ \\ ${ }^{1}$ Associate professor of public policy - Director of POLIS (Observatorio de Políticas Públicas) Universidad Icesi, \\ Colombia; Universidad ICESI - POLIS, Cali, Colombia \\ ${ }^{2}$ Universidad ICESI, Researcher of POLIS (Observatorio de Políticas Públicas) Universidad Icesi, Colombia. \\ ${ }^{3}$ Universidad ICESI, Researcher of POLIS (Observatorio de Políticas Públicas) Universidad Icesi, Colombia. \\ Correspondence: Lina Martínez, Universidad ICESI - POLIS, Cali, Colombia
}

Received: February 18, 2021 Accepted: March 31, 2021 Online Published: April 25, 2021

doi:10.5539/res.v13n2p72

URL: https://doi.org/10.5539/res.v13n2p72

\begin{abstract}
COVID-19 pandemic is harming many social and economic spheres beyond physical health. The subjective well-being of the population (positive emotions and life satisfaction) and the prevalence of stressors affecting good mental health like worry, depression, and anxiety are increasing worldwide. This analysis presents evidence of subjective well-being and mental health in Colombia, South America, during the current crisis. The data for this analysis comes from an online survey released after one month of quarantine. In total, 941 adults participated in the study. Results show that women are more affected by their well-being and experience more often worry, depression, and anxiety than males. In particular, younger women and from the lower socioeconomic strata. Respondents identify three primary concerns because of the pandemic: i) financial consequences, ii) health (personal and loved one's health), and iii) productivity. Respondents are, on average, more concerned for the health of loved ones than their health. 49\% of study participants report having an income reduction as a consequence of the pandemic, but women in all subgroups analyzed are more affected than males. In terms of productivity -working remotely-, educated people, and from 50+ age range, feels more productive working from home. Evidence from this analysis contributes to the broader research of the consequences of COVID-19 on the well-being of the population. Evidence comes from a country in the global South with high population ratings of subjective well-being, happiness, and life satisfaction before the pandemic.
\end{abstract}

Keywords: subjective well-being, mental health, COVID-19, Colombia, gender

\section{Introduction}

Coronavirus pandemic is hitting the entire world severely with significant consequences through live losses and economic stagnation. The pandemic has shifted its epicenter, starting in China and now with devastating outcomes in Latin America, a region that only until a few decades ago is experiencing the transition from low to middle income in the vast majority of its countries (OECD, 2019). With low spending on their health system and lack of government capacity for implementing a broad range of social policies for the poor, Latin America will suffer long-lasting consequences (Blackman et al., 2020). Some population groups, like women and the poor, will be more vulnerable to the pandemic's economic and social aftermath, deepening existing inequalities (World Bank, 2020). This crisis harms the physical and mental health of the population, affecting the positive reports of high levels of subjective well-being and life satisfaction in the region (Rojas, 2016).

Latin America is experiencing a steady rise in the number of new cases and deaths as a consequence of COVID-19 (Marquez, Aguilera \& Calderon, 2020). By May 2020, The World Health Organization declared Latin America the new epicenter of the pandemic. In early July, over three million cases were in the official records, and more than 130,000 people have died (Horton, 2020). Latin America is a region facing several challenges during this pandemic, ranging from the low capacity of the public health system to the high prevalence of poverty and inequality (Blackman et al., 2020).

Latin America experimented an important social and economic prosperity over the last two decades but is still the most unequal region in the world (OECD, 2019). The prevalence of poverty and the need of the poor to bring food to the table, have contributed to the inefficacy of lockdowns implemented across the region since March. Besides the economic considerations that are a significant challenge during this pandemic, the health system in the region cannot test and monitor the pandemic's trajectory as other countries in the global North, given the 
scarce resources and reduced health care infrastructure. By 2017 per-person health spending in the region was a quarter compared with the spending on health on OECD countries (OECD, 2020).

Before the pandemic, the reports in Latin America of subjective well-being and life satisfaction, which are core components of good mental and physical health, have remained high (Beytía, 2016). People had self-reported as very happy and satisfied with their life despite poverty, inequality, and exclusion from the welfare system (Ateca-Amestoy, 2016). The positive subjective well-being reported in Latin America has strong correlations with good physical and mental health (Florenzano \& Dussaillant, 2016; Elizondo-Lara \& Rojas, 2016) income and job satisfaction (Montero \& Rau, 2016), and family relations (Rojas \& Elizondo-Lara, 2016). The Coronavirus pandemic's pervasiveness has direct and negative impacts on all the factors associated with high subjective well-being in the region. Many have loosed their loved ones, experimented with illness, lost their jobs, increase stress, anxiety, and depression, and family relations are exposed to additional stressors.

This pandemic is a very recent episode and is uncertain about the long-term implications for the population's well-being and mental health. The preliminary evidence available shows important changes in the mental health of the population worldwide, with reports of increasing anxiety, depression, and stress during this pandemic (Wang, Pan, Wan, 2020; Wang, Pan, Wan, 2020; Cao, Fang, Hou, 2020; El-Zoghby, Soltan, Salama, 2020; Losada-Baltar, et al.,2020; Sønderskov, Dinesen, Santini, Østergaard, 2020).

Intending to contribute to the global discussion of the implications of COVID-19 in people's well-being and mental health, we present evidence from Colombia. In this analysis, we discuss information from an online survey conducted in the country after three weeks of a strict confinement. The survey inquired about two factors related to subjective well-being: i) how home confinement relates to life satisfaction and negative emotions like depression, worry, and anxiety; and ii) what are the main people's concerns associated with the crisis. We report that COVID-19 is taking a negative toll on people's well-being with more negative consequences on women. Compared with previous national measures of well-being, there are important reductions in life satisfaction and happiness, and there is an increase in worry and depression.

This analysis is organized in six sections, being this introduction the first part. Second section presents a brief summary of the evidence available about subjective well-being and emotional distress during the COVID-19 pandemic. Third section describes the general Colombian context during this crisis. Research questions and the study design are presented afterwards, followed by results and a discussion of the conclusions.

\section{Subjective Well-being, Emotional Distress and the Pandemic}

The notion of subjective well-being is broad. It encompasses good mental states, the evaluations -positive and negativethat people make about their lives and affective reactions to experiences. It also includes people's evaluations about different life aspects, as well as "purpose" in life (OECD, 2013). The bourgeoning literature on life satisfaction that has spurred over the last decades (Diener et al., 2018), have shown consistently that life satisfaction is highly correlated with a good mental and physical health (Veenhoven, 2008; Blanchflower \& Oswald, 2008; Cummins, 2010), social relations (Lamu \& Olsen, 2016), job stability and income (Diener et al., 2015), and government performance (Leyden et al., 2011; Florida et al., 2013). The COVID-19 crisis had affected negatively all the aspects correlated with our well-being. COVID-19 is a direct threat to the physical health, and the draconian measures taken by governments as quarantines are a direct threat to our mental health (De Lima et al., 2020). The countless social distancing measures implemented across the world impede the social closeness that increases life satisfaction. The economic consequences of COVID-19 have rendered many jobless and is adding pressure to the financial conditions of millions of households. Moreover, this crisis is unveiling the limited capacities of governments to help, solve, and control a crisis of this dimension (Greer et al., 2020). COVID-19 in short, is affecting the fabric that constitute our well-being.

We know little about how this crisis will affect people's well-being and mental health in the long term. The recent evidence shows that the crisis caused by COVID-19 has a significant effect on the emotional distress and subjective well-being reduction of people around the world. The losses caused by COVID-19 in the number of deaths, contagion, and the economic consequences are unprecedented. Some have even called the crisis caused by COVID-19 "the largest physiological experiment even conducted" (Van Hoof, 2020). The evidence available about the effects of COVID-19 of emotional distress shows that the disruption on daily activities, career trajectories, peer socialization, and the ability to perform daily activities have increased stress, anxiety, and depression (Zhai \& Du, 2020). Evidence from China suggests that the impact of COVID-19 on mental health is moderate to severe with respondents reporting spikes in anxiety and depression (Cao et al., 2020). Similar findings are reported in other latitudes across the world (Losada-Baltar et al., 2020; Huckins et al., 2020; Brooks et al., 2020; Zandifar \& Badrfam, 2020).

Social confinement, despite the negative toll on mental health and the economy, remains the best non-pharmacological alternative to reduce contagion. However, the correlation of this restrictive measures with the prevalence of negative 
emotions is reported across different populations ranging from school-aged children to the elderly (Hossain, et al., 2020).

Life satisfaction has been also negatively affected during the COVID-19 crisis. In a world-wide study about social participation and life satisfaction during confinement, researchers conclude that the interruptions of daily living, social contact and interactions, and isolation negatively impacts life satisfaction of the respondents (Ammar et al., 2020).

The preliminary evidence points to the same direction: COVID-19 is affecting negatively people's well-being and life satisfaction. However, is still unknown the long-lasting consequences, the differences by different population groups, and more importantly, is necessary more evidence to provide more robust evidence for policy-making and program intervention for the possible consequences of this crisis.

\section{Colombian Context During the Pandemic}

Taking all together, Colombia is one of the countries in Latin America currently with the highest contagion rates. By late November, the health ministry reported over 34,000 deaths and over 1,2 million cases (Ministerio de Salud, 2020).

Generaly speaking, Coronavirus in Colombia is mostly an urban phenomenon. Large cities like Bogotá (over 8 million inhabitants), and Cali and Medellin report the largest share of cases. In the country, the implementation of draconian measures started early. The first case of Coronavirus was reported on March 6th, the school system closed on March 14th, the elderly was ordered to stay at home on March 20th, and national quarantine was imposed on March $25^{\text {th }}$ (Ignatius, 2020). The quarantine in the country extended several times. Initially, the government order was for three weeks and gradually extended until September $1^{\text {st }}$, totaling 6 months, one of the longest quarantines in the world during the COVID-19 crisis (Taylor, 2020). Since May, some workers are allowed to work, but there were severe penalty fees (over a monthly minimum wage) for those who did not complain about the quarantine. Despite the enforcement, many people were on the streets. The employment rate for May 2020 was 21,4\%, increasing almost 11 percentage points in the same period in 2019 (DANE, 2020a) and the highest amongst countries in the OECD (OECD, 2020). This crisis is creating the major economic crisis in recent history in the country.

Regarding subjective well-being and mental health, preliminary results of a phone survey conducted by the National Statistics Office (DANE) in the country, show the prevalence of negative emotions such as worry, tiredness, loneliness, and sadness in the population during this crisis. The prevalence of negative emotions is higher amongst women. On average, women report a higher prevalence of feeling worried (38,6\% vs. 35,9\% for males), tired (18,1\% vs. 15,3\% for males), lonely (12,2\% vs. 9,9\% for males), and sad (20,6\% vs. $15 \%$ for males). Negative emotions are also more prevalent amongst unemployed and women without income (DANE, 2020a).

\section{Study Design}

The main purpose of this study is to provide insights on two factors generated by the COVID-19 crisis: i) how home confinement, relates to life satisfaction and negative emotions like depression, worry, and anxiety; and ii) what are the main people's concerns associated to the crisis.

To answer those questions, researchers created an online survey released in Colombia in April 2020, three weeks after strict confinement. POLIS, the Observatory of Public Policies of Universidad Icesi, designed the survey, using the same metrics of a panel study of subjective well-being in Cali, the third-largest city in the country. Since 2014, POLIS measures life satisfaction and subjective well-being every year $(2014$ - 2019) through a yearly population survey called CaliBRANDO (Martínez, 2017). The questionnaire used standard socioeconomic variables coming from the national statistical office in Colombia (DANE, 2020b). For the measures of subjective well-being and the prevalence of negative emotions, the questionnaire included subjective well-being core measures battery recommended by the Organization of Economic Co-operation and development (OECD, 2013 - annex A).

The online survey reported in this article inquired about COVID-19 consequences on the well-being and mental health of the population. Typeform, an online server for pooling, was the platform used for collecting the data. Alongside the survey, researchers created a short video explaining the motivations for conducting the study and presented general results of the CaliBRANDO survey and national statistics of subjective well-being. The video asked respondents to participate in the study to explore how the pandemic and the quarantine affected life satisfaction, worry, depression, and anxiety to track the changes in subjective well-being in the population before and during the pandemic. As a reward for participation, participants downloaded a gratitude journal and a stress management diary designed for this study at the end of the survey. For this study, a web platform was designed to display the survey, videos, and reports of life satisfaction and subjective well-being in Cali and Colombia ${ }^{1}$. The survey circulated through a snowball sampling strategy. Social networks and postings from journalists in the country were pivotal for its distribution. In total, 941 adults in Colombia participated in the study.

\footnotetext{
${ }^{1}$ https://www.icesi.edu.co/polis/investigaciones/seccionsalud/salud-covid-19.php
} 
The survey was available to all adults (18 years and older) in the country who wanted to participate. Most of the respondents of this study were female, from medium-high socioeconomic status, with higher educational attainment. The survey circulated mainly through a local newspaper (Dario El País) and posted from journalists, generally followed by individuals with higher educational attainment. This survey does not represent the general population in Colombia, the average years of education in the country is 13 years (high school and some technical education), and $51 \%$ are females (DANE, 2021).

The questionnaire had seven sociodemographics questions (city, gender, age, education, occupation, socioeconomic strata, and race/ethnicity). For measuring well-being, we used life satisfaction measures and the prevalence of the most common negative emotions affecting good mental health (worry and depression). This survey used the standardized and validated scale of core measures of well-being (OECD, 2013). For these questions, respondents were asked:

- On a scale, 0 -10, zero means you feel "not at all satisfied" and 10 means you feel "completely satisfied" Overall, how satisfied are you with life as a whole these days?

- How you felt yesterday on a scale from 0 to 10. Zero means you did not experience the feeling "at all" yesterday while 10 means you experienced the feeling "all the time". Yesterday you felt:

1. Worried

2. Depressed

The questionnaire also includes questions about feelings of anxiety the day before (scale 0-10) and a set of questions regarding concerns and direct affections. Respondents were asked for the following (scale 0-10): worry for their health; worry for the health of loved ones; feeling productive working from home; worry about economic consequences of COVID-19.

Respondents gave their consent to use the information for academic purposes and this survey is covered by the ethics committee approval of Universidad Icesi (code \# 311). A policy brief aiming at informing local policymakers was distributed in late May (POLIS, 2020).

Raw data, questionnaire and the materials associated with this study are available at Mendeley data (DOI: 10.17632/3z6k2r3rmd.2) and there is an open access publication presenting the details of this survey (Martínez et al., 2020). This paper presents descriptive statistics of mean differences by gender, age, socioeconomic strata and educational attainment. Analysis are performed using Stata 14. Differences by gender are estimated with t-test setting standard significance levels in social sciences (Lewis-Beck et al., 2003).

\section{Results}

Participants of the survey were mostly women (63\%), educated, young (18 - 35 years old), and middle socioeconomic strata. The proportion of self-employment and formal employment are relatively equally distributed. In this sample, $63 \%$ of females report technical or professional education. Table 1 present the general characteristics of the population participating in the survey.

Table 1. Demographic characteristics of participants

\begin{tabular}{lcc}
\hline Gender & & $\mathrm{N}$ \\
\hline \hline Female & $63 \%$ & 595 \\
Male & $37 \%$ & 346 \\
\hline Age & & \\
\hline \hline 18 - 35 years & $57 \%$ & 530 \\
36 - 50 years & $24 \%$ & 217 \\
$50+$ & $19 \%$ & 176 \\
\hline Socioeconomic strata (SES) & & \\
\hline \hline High SES & $34 \%$ & 321 \\
Middle SES & $49 \%$ & 465 \\
Low SES & $17 \%$ & 156 \\
\hline Educational attainment & & \\
\hline \hline High school or less & $7 \%$ & 74 \\
Technical - professional education & $92 \%$ & 868 \\
\hline Employed & $44 \%$ & 414 \\
Self-employed - informal worker & $40 \%$ & 373 \\
Other & $16 \%$ & 155 \\
\hline \hline
\end{tabular}




\subsection{Subjective Well-being}

Before COVID-19, national reports of subjective well-being were high in Colombia. National measurements collected between 2015 and 2018 reported high levels of life satisfaction and positive emotions like happiness (Castro, Puerta \& Castañeda, 2019). The average life satisfaction score in Colombia during 2015 - 2018 was 8,6 without significant variations by year. This score is one unit higher than OECD countries scoring, on average, 7,5 in the life satisfaction measure during the same period (OECD, 2020). Negative emotions like worry were, on average, 3.8 on a scale of 0-10 with differences by gender: 3.9 for males and 5.7 for females. At the national level, the affect balance measure (positive emotions versus negative emotions like worry or depression), was on average, 7,7 , indicating a higher prevalence of subjective well-being (life satisfaction, happiness, and positive emotions) within the population than negative emotions (worry and depression). Similar numbers are reported in other cities in Colombia (Martínez \& Short, 2020).

Within the sample who took part in the study during the pandemic of COVID-19, the life satisfaction score was, on average, 7,5 without important differences by gender or population group (age, socioeconomic strata, education, or employment). Females report on average a higher prevalence of worry than males, mainly the younger and less educated, in which differences are significant. For depression and anxiety, we find the same pattern. Women report negative emotions with higher prevalence than males. Younger women (18 -35-age range) report a higher prevalence of depression, whereas middle-aged women (36-50 age range) report more prevalence of anxiety. Less-educated women report a higher prevalence of worry, depression, and anxiety than males with the same educational attainment, and those differences are significant. Table 2 presents the results of life satisfaction and feelings of depression, worry, and anxiety during the quarantine.

Table 2. Life satisfaction, worry, depression, and anxiety by gender

\begin{tabular}{|c|c|c|c|c|c|c|c|c|c|c|c|c|}
\hline & \multicolumn{3}{|c|}{ Life satisfaction } & \multicolumn{3}{|c|}{ Worry } & \multicolumn{3}{|c|}{ Depress } & \multicolumn{3}{|c|}{ Anxiety } \\
\hline & Male & Female & Diff & Male & Female & Diff & Male & Female & Diff & Male & Female & Diff \\
\hline $18-35$ years & 7,5 & 7,2 & - & 4,9 & 5,6 & $* * *$ & 3,1 & 3,7 & $*$ & 5 & 6 & - \\
\hline $36-50$ years & 8 & 7,8 & - & 4,9 & 5,2 & - & 2,8 & 3,2 & - & 5,5 & 7,1 & $*$ \\
\hline $50+$ & 7,9 & 8,2 & - & 5,4 & 4,8 & - & 2,7 & 2,5 & - & 5,8 & 6,1 & - \\
\hline & & & & & & & & & & & & - \\
\hline High SES & 8 & 7,8 & - & 5,1 & 5,3 & - & 2,7 & 31 & - & 5,2 & 4,7 & \\
\hline Middle SES & 7,5 & 7,3 & - & 4,8 & 5,3 & - & 2,9 & 3,5 & $*$ & 5,3 & 5,9 & - \\
\hline Low SES & 7,3 & 7,4 & - & 5,2 & 5,7 & - & 3,6 & 3,8 & - & 5,9 & 6,3 & - \\
\hline High school or less & 7,7 & 7,5 & - & 4,2 & 5,7 & $*$ & 2,5 & 4,3 & $*$ & 5,7 & 5,8 & $*$ \\
\hline Technical - professional education & 7,7 & 7,5 & - & 5,1 & 5,3 & - & 3 & 3,4 & - & 5,1 & 6 & - \\
\hline Employed & 7,8 & 7,8 & - & 5,1 & 5,4 & - & 2,8 & 3,3 & - & 6,2 & 6,6 & - \\
\hline Self-employed - informal worker & 7,6 & 7,5 & - & 4,8 & 5,4 & - & 2,5 & 3 & - & 6,5 & 6,9 & - \\
\hline Other & 7,4 & 7,2 & - & 4,9 & 5,3 & - & 3,4 & 3,8 & - & 5,7 & 6 & - \\
\hline
\end{tabular}

*** $\mathrm{p}>0.99 * * \mathrm{p}>0.95 * \mathrm{p}>0.90$

\subsection{The Concerns Caused by the Pandemic}

The survey inquired about different aspects that could increase concerns and worries, such as government measures (quarantine and social distancing), the pervasiveness of negative news in the media, universal adherence to restrictive measures, financial consequences, productivity, and concerns about the possibility of being infected by the virus. Three concerns stand out in the results: i) the financial consequences of the pandemic; ii) concerns for the infection in physical health (personal health and loved ones); and iii) productivity.

\subsubsection{Financial Consequences of COVID-19}

The primary concern reported among respondents was the financial consequences of the pandemic. Moreover, $49 \%$ of the 
people answering the survey report that their income was affected. Both males and females in all population groups analyzed are equally concerned with economic issues; however, women report a significant affection for their income. In almost all the subgroups analyzed, women report that their income is affected in a higher proportion than males. Table 3 presents the results.

Table 3. Income reduction and concerns about financial consequences by gender

\begin{tabular}{|c|c|c|c|c|c|c|}
\hline & \multicolumn{3}{|c|}{$\begin{array}{l}\text { Your income is affected by COVID-19 } \\
\text { (Yes - No question) }\end{array}$} & \multicolumn{3}{|c|}{$\begin{array}{c}\text { Concerned about the financial } \\
\text { consequences of COVID-19 } \\
\text { (Average scale } 0-10 \text { ) }\end{array}$} \\
\hline & Male & Female & Diff & Male & Female & Diff \\
\hline Male & $46 \%$ & - & - & 8,7 & - & - \\
\hline Female & - & $51 \%$ & - & - & 8,6 & - \\
\hline $18-35$ years & $36 \%$ & $64 \%$ & $* * *$ & 8,8 & 8,7 & - \\
\hline $36-50$ years & $30 \%$ & $70 \%$ & $* * *$ & 8,8 & 8,6 & - \\
\hline $50+$ & $44 \%$ & $55 \%$ & - & 8,6 & 8,1 & - \\
\hline High SES & $38 \%$ & $62 \%$ & $* * *$ & 8,9 & 8,7 & - \\
\hline Middle SES & $34 \%$ & $66 \%$ & $* * *$ & 8,6 & 8,6 & - \\
\hline Low SES & $35 \%$ & $65 \%$ & $* * *$ & 8,6 & 8,3 & - \\
\hline High school or less & $33 \%$ & $67 \%$ & $* *$ & 8,3 & 8,2 & - \\
\hline Technical - professional education & $36 \%$ & $64 \%$ & $* * *$ & 8,7 & 8,6 & - \\
\hline Employed & $44 \%$ & $55 \%$ & - & 8,7 & 8,7 & - \\
\hline Self-employed - informal worker & $36 \%$ & $64 \%$ & $* * *$ & 8,8 & 8,5 & - \\
\hline Other & $30 \%$ & $70 \%$ & $* * *$ & 8,6 & 8,6 & - \\
\hline
\end{tabular}

*** $\mathrm{p}>0.99 * * \mathrm{p}>0.95 * \mathrm{p}>0.90$

\subsubsection{Health}

Participants of the survey report a more significant concern for the physical health of loved ones than their health. On average, on a scale $0-10$, respondents rate their concern for personal health on 6 , whereas the concerns about the health of loved ones are 8,5. There are no differences by gender in almost all categories analyzed; however, younger women report greater concern for the health of loved ones than males. Table 4 presents the results by gender. 
Table 4. Concerns about personal and loved ones health by gender

I'm concerned about my health

(Average scale 0-10)
I'm concerned for the health of my loved

ones (Average scale 0-10)

\begin{tabular}{|c|c|c|c|c|c|c|}
\hline & Male & Female & Diff & Male & Female & Diff \\
\hline High school or less & 6,2 & 6,3 & - & 8,5 & 8,8 & - \\
\hline Technical - professional education & 6,1 & 6,1 & - & 8,2 & 8,4 & - \\
\hline $18-35$ years & 5,8 & 6,1 & - & 8,4 & 8,7 & $*$ \\
\hline $36-50$ years & 6,2 & 6,2 & - & 7,9 & 8,3 & - \\
\hline $50+$ & 6,5 & 6,1 & - & 8 & 7,8 & - \\
\hline High SES & 5,8 & 6 & - & 8,3 & 8,4 & - \\
\hline Middle SES & 6,3 & 6,2 & - & 8,3 & 8,5 & - \\
\hline Low SES & 6 & 6,1 & - & 7,8 & 8,5 & - \\
\hline Employed & 6 & 6 & - & 8,4 & 8,4 & - \\
\hline Self-employed - informal worker & 6,2 & 6,2 & - & 8,1 & 8,4 & - \\
\hline Other & 6 & 6,2 & - & 8,1 & 8,6 & $*$ \\
\hline
\end{tabular}

$* * * \mathrm{p}>0.99 * * \mathrm{p}>0.95 * \mathrm{p}>0.90$

\subsubsection{Productivity}

In terms of productivity (working from home), the participants of this study, rate their professional productivity at 6 (scale $0-10)$. Older (50+ years) and from higher socioeconomic status are the ones rating higher in this component. Women with less educational attainment and from lower socioeconomic strata are the ones rating lower on their productivity working remotely. In terms of gender differences, professional educated and formally employed women report a higher feeling of being productive working remotely.

Table 5. Feeling productive working remotely by gender

\begin{tabular}{lccc}
\hline & Feels productive working remotely (average scale 0 - 10) \\
\hline \hline & Male & Female & Diff \\
High school or less & & & - \\
Technical - professional education & 4,8 & 4,4 & - \\
\hline & 4,9 & 5,4 & - \\
18 - 35 years & & & - \\
36 - 50 years & 4,4 & 4,7 & $*$ \\
$50+$ & 5,8 & 5,9 & - \\
\hline & 5,8 & 6,5 & - \\
High SES & & 5,7 & $*$ \\
Middle SES & 5,5 & 5,3 & - \\
Low SES & 4,6 & 4,3 & - \\
\hline
\end{tabular}




\section{Discussion and Conclusions}

We report on an online survey about the consequences of subjective well-being caused by the COVID-19 pandemic in Colombia. Over 900 adults participated in this study, reporting an average score of 7,5 on life satisfaction, one unit below previous national measures. Results from this sample also suggest an increase in the prevalence of negative emotions like worry and depression, particularly amongst women. Compared to males, younger and less educated women report higher worry, depression, and anxiety. Results show the prevalence of worry, anxiety, and depression, which are negative emotions that affect the population's mental health.

Study results align with the evidence available reporting the negative mental health consequences due to the COVID-19 pandemic worldwide. There are consistent reports of an increase of negative emotions like depression and anxiety in different contexts with a higher prevalence amongst women (Zhai \& Du, 2020; Cao et al., 2020; (Losada-Baltar et al., 2020; Huckins et al., 2020; Brooks et al., 2020; Zandifar \& Badrfam, 2020). The current crisis broadly affects the population's mental health through different mechanisms. First, the pandemic increases anxiety given the constant worry of being infected, the probability of infecting others, and the possibility of loved ones being infected. The pandemic also affects mental health through concerns about financial stability or unemployment. Another mechanism related to COVID-19 is the burden of domestic work and responsibilities that increase the workload and daily stress (Helliwell et al., 2021).

Similar to the evidence available, the results of this study show three concerns about the consequences of the pandemic: financial consequences, concerns for personal and loved one's health, and labor productivity. Generally speaking, males and females are equally concerned about all aspects; however, women are significantly more penalized than males in terms of earnings. Income reductions because of the pandemic were reported for almost half of the respondents in this survey, but women are more affected than males. Women from all subgroups analyzed report a negative affection on their income, and the differences are significant compared to the income affection reported by males. In particular, women from middle age (35 -50 years old), lower socioeconomic strata, and lower educational attainment. In terms of productivity working from home, poorer and less educated women report the lowest ratings on productivity

These results suggest that women are more affected by their well-being, mental health, and income during this crisis in the context studied. Women are more penalized than males, particularly on their ability to earn their income, on the prevalence of worry, and depression, and being less productive working from home. Gender inequalities, which have been deep in Latin America with women making less than their males' counterparts, and taking more responsibilities at home with the care of children and elderly, plus house chores (UN, 2019), may increase due to the current pandemic.

We are aware of the limitations of an online study and the self-selection bias it entails. This sample is not representative of the country populations by excluding population from the lower socioeconomic strata who do not have access to the internet or do not have the literacy to fill out an online survey.

With this analysis, we aim at contributing to a broader analysis of the consequences of COVID-19 on the different economic and social aspects that burden the worldwide population.

\section{Data Availability Statement}

Data for this analysis is publicly available at Mendey Data, DOI:10.17632/3z6k2r3rmd.2. Likewise, detailed information about questionnaire, measures and descriptive statistics, are published on Data in Brief under the tittle: Subjective Well-being and Mental Health during the COVID-19 pandemic: Data from three population groups in Colombia.

\section{References}

Amestoy, V. A., García-Muñoz, T., \& Egido, A. I. M. (2016). Individual and social dimensions of subjective well-being: evidence across Latin-American Countries. In Handbook of Happiness Research in Latin America (pp. 357-388). Springer, Dordrecht. https://doi.org/10.1007/978-94-017-7203-7_21

Ammar, A., Chtourou, H., Boukhris, O., Trabelsi, K., Masmoudi, L., Brach, M., ... \& ECLB-COVID19 Consortium. (2020). COVID-19 home confinement negatively impacts social participation and life satisfaction: a worldwide multicenter study. International journal of environmental research and public health, 17(17), 6237. https://doi.org/10.3390/ijerph17176237

Beytía, P. (2016). The singularity of Latin American patterns of happiness. Handbook of happiness research in Latin America, 17-29. https://doi.org/10.1007/978-94-017-7203-7_2

Blackman, A., Ibañez, A. M., Izquierdo, A., Keefer, P., Moreira, M. M., Schady, N., \& Serebrisky, T. (2020). La política pública frente al COVID-19: recomendaciones para América Latina y el Caribe (Vol. 810). Inter-American Development Bank. https://doi.org/10.18235/0002302

Blanchflower, D. G., \& Oswald, A. J. (2008). Hypertension and happiness across nations. Journal of health economics, 


\section{7(2), 218-233. https://doi.org/10.1016/j.jhealeco.2007.06.002}

Brooks, S. K., Webster, R. K., Smith, L. E., Woodland, L., Wessely, S., Greenberg, N., \& Rubin, G. J. (2020). The psychological impact of quarantine and how to reduce it: rapid review of the evidence. The lancet, 395(10227), 912-920. https://doi.org/10.1016/S0140-6736(20)30460-8

Cao, W., Fang, Z., Hou, G., Han, M., Xu, X., Dong, J., \& Zheng, J. (2020). The psychological impact of the COVID-19 epidemic on college students in China. Covid-19.Conacyt.Mx. https://doi.org/10.1016/j.psychres.2020.112934

Castro, F., Puertam, N., \& Castañeda, C. (2019). Subjective well-being analysis: the Colombian case. In Public Policy Observatory - Icesi University, ed., Life Satisfaction an Expanding Research Area. Cali, Colombia: Icesi University, 57-62.

COVID, C. (19). Dashboard by the center for systems science and engineering (CSSE) at Johns Hopkins University (JHU).

Cummins, R. A. (2010). Fluency disorders and life quality: Subjective well-being vs. health-related quality of life. Journal of fluency disorders, 35(3), 161-172. https://doi.org/10.1016/j.jfludis.2010.05.009

DANE (2020b). Encuesta Nacional de Hogares. Microdatos y manuales técnicos. Retrieved from: https://www.dane.gov.co/index.php/estadisticas-por-tema/mercado-laboral/encuesta-nacional-de-hogares

DANE (2021). Estadísticas por tema- Educación. Retrieved from: https://www.dane.gov.co/index.php/estadisticas-por-tema/educacion

DANE. (2020a). Encuesta Pulso Social - Resultados tercera ronda. [Diapositivas]. https://www.dane.gov.co/index.php/estadisticas-por-tema/encuesta-pulso-social

DANE. Gran Encuesta Integrada de Hogares (GEIH) Mercado laboral. https://www.dane.gov.co/index.php/estadisticas-por-tema/mercado-laboral/empleo-y-desempleo Published May 2020. Accessed July $17^{\text {th }}, 2020$.

de Lima, C. V. C., Cândido, E. L., da Silva, J. A., Albuquerque, L. V., de Menezes Soares, L., do Nascimento, M. M., ... \& Neto, M. L. R. (2020). Effects of quarantine on mental health of populations affected by Covid-19. Journal of affective disorders, 275, 253-254. b

Diener, E., Oishi, S., \& Lucas, R. E. (2015). National accounts of subjective well-being. American psychologist, 70(3), 234. https://doi.org/10.1037/a0038899

Diener, E., Oishi, S., \& Tay, L. (2018). Advances in subjective well-being research. Nature Human Behaviour, 2(4), 253. https://doi.org/10.1038/s41562-018-0307-6

Elizondo-Lara, M., \& Rojas, M. (2016). The Impact of Economic Growth on the Prevalence of Health Problems in Latin America. In Handbook of Happiness Research in Latin America (pp. 515-528). Springer, Dordrecht. https://doi.org/10.1007/978-94-017-7203-7_29

El-Zoghby, S. M., Soltan, E. M., \& Salama, H. M. (2020). Impact of the COVID-19 pandemic on mental health and social support among adult Egyptians. Journal of community health, 45, 689-695. https://doi.org/10.1007/s10900-020-00853-5

Florenzano, R., \& Dussaillant, F. (2016). The Determinants of Mental Health: Empirical Evidence from Chile. In Handbook of Happiness Research in Latin America (pp. 479-488). Springer, Dordrecht. https://doi.org/10.1007/978-94-017-7203-7_27

Florida, R., Mellander, C., \& Rentfrow, P. J. (2013). The happiness of cities. Regional Studies; 47(4), 613-627. https://doi.org/10.1080/00343404.2011.589830

Greer, S. L., King, E. J., da Fonseca, E. M., \& Peralta-Santos, A. (2020). The comparative politics of COVID-19: The need to understand government responses. Global public health, 15(9), 1413-1416. https://doi.org/10.1080/17441692.2020.1783340

Helliwell, J., Layard, R., \& Sachs, J., De Neve, J., Aknin, L., \& Wang, S. (2021). World happiness Report 2021. World Happiness. Retrieved from: https://worldhappiness.report/ed/2021/

Horton, J. (2020). Coronavirus: What are the numbers out of Latin America. BBC News, 28.

Hossain, M. M., Sultana, A., \& Purohit, N. (2020). Mental health outcomes of quarantine and isolation for infection prevention: a systematic umbrella review of the global evidence. Available at SSRN 3561265. https://doi.org/10.2139/ssrn.3561265 
Huckins, J. F., DaSilva, A. W., Wang, W., Hedlund, E., Rogers, C., Nepal, S. K., ... \& Campbell, A. T. (2020). Mental health and behavior of college students during the early phases of the COVID-19 pandemic: longitudinal smartphone and ecological momentary assessment study. Journal of medical Internet research, 22(6), e20185. https://doi.org/10.2196/20185

Ignatius, D. (2002). Colombia planned well for the pandemic. The region is reeling. The Washington Post. Retrieved from https://www.washingtonpost.com/opinions/2020/06/22/colombia-planned-well-pandemic-region-is-reeling/

Lamu, A. N., \& Olsen, J. A. (2016). The relative importance of health, income and social relations for subjective well-being: An integrative analysis. Social Science \& Medicine, 152, 176-185. https://doi.org/10.1016/j.socscimed.2016.01.046

Lewis-Beck, M., Bryman, A. E., \& Liao, T. F. (2003). The Sage encyclopedia of social science research methods. Sage Publications. https://doi.org/10.4135/9781412950589

Leyden, K. M., Goldberg, A., \& Michelbach, P. (2011). Understanding the pursuit of happiness in ten major cities. Urban Affairs Review, 47(6), 861-888. https://doi.org/10.1177/1078087411403120

Losada-Baltar, A., Jiménez-Gonzalo, L., Gallego-Alberto, L., Pedroso-Chaparro, M., Fernandes-Pires, J., \& Márquez-González, M. (2020). "We're staying at home". Association of self-perceptions of aging, personal and family resources and loneliness with psychological distress during the lock-down period of COVID-19. J Gerontol B Psychol Sci Soc Sci., 20(20), 1-7. https://doi.org/10.1093/geronb/gbaa048

Marquez, P., Aguilera, S., Calderon, L. (2020). Have South and Central America become the new coronavirus (COVID-19) epicenter?

Martínez, L. (2017). Life satisfaction data in a developing country: CaliBRANDO measurement system. Data in brief, 13, 600. https://doi.org/10.1016/j.dib.2017.06.038

Martínez, L., \& Short, J. R. (2020). Life satisfaction in the city. Scienze Regionali, 0-0.

Martínez, L., Valencia, I., \& Trofimoff, V. (2020). Subjective well-being and mental health during the COVID-19 pandemic: Data from three population groups in Colombia. Data in brief, 32, 106287. https://doi.org/10.1016/j.dib.2020.106287

$\begin{array}{lllll}\text { Ministerio } & \text { de } & \text { Salud. Conavirus } & - & \text { Covid-19. }\end{array}$ https://www.minsalud.gov.co/salud/publica/PET/Paginas/Covid-19_copia.aspx . Published March 2020. Accessed July $17^{\text {th }}, 2020$.

Montero, R., \& Rau, T. (2016). Relative Income and Job Satisfaction in Chile. In Rojas M, ed., Handbook of Happiness Research in Latin America. Ciudad de México, México: Springer, 205-218. https://doi.org/10.1007/978-94-017-7203-7_13

Observatorio de políticas públicas, POLIS, Universidad Icesi- Cali, Colombia.

OECD, CEPAL, CAF and European Union. Perspectivas económicas de América Latina 2019: Desarrollo en transición. Paris, France: OECD Publishing; 2019. https://doi.org/10.1787/g2g9ff1a-es

OECD. How's Life? 2020 Measuring Well-being. Paris, France: OECD Publishing; 2020. https://doi.org/10.1787/9870c393-en

OECD. Latin America and the Caribbean countries need to spend more and better on health to be better able to face a major health emergency like COVID-19 effectively. https://www.oecd.org/health/latin-america-and-the-caribbean-countries-need-to-spend-more-and-better-on-health-t o-be-better-able-to-face-a-major-health-emergency-like-covid-19-effectively.htm . Published June $16^{\text {th }}, 2020$. Accessed July $17^{\text {th }}, 2020$.

OECD. OECD Employment Outlook 2020: Worker Security and the COVID-19 Crisis. Paris, France: OECD Publishing; 2020. https://doi.org/10.1787/1686c758-en

OECD. OECD guidelines on measuring subjective well-being. Paris, France: OECD Publishing; 2013. https://doi.org/10.1787/9789264191655-en

POLIS (2020) Bienestar y salud mental en época de crisis y pandemia. Datos en Breve No. 14.

Rojas, M. (2016). Happiness, Research, and Latin America. In Handbook of happiness research in Latin America. In Rojas M, ed. Handbook of Happiness Research in Latin America. Ciudad de México, México: Springer, 1-13. https://doi.org/10.1007/978-94-017-7203-7_1 
Rojas, M., \& Elizondo-Lara, M. (2016). The role of relational goods in the relationship between illnesses and satisfaction in Latin America. In Handbook of happiness research in Latin America (pp. 179-190). Springer, Dordrecht. https://doi.org/10.1007/978-94-017-7203-7_11

Sønderskov, K. M., Dinesen, P. T., Santini, Z. I., \& Østergaard, S. D. (2020). The depressive state of Denmark during the COVID-19 pandemic. Acta neuropsychiatrica, 1-3. https://doi.org/10.1017/neu.2020.15

Taylor. (2020). Retrieved from https://www.abc.net.au/news/2020-11-09/colombia-six-month-coronavirus-lockdown-price-to-pay/12855242

UN Women. Progress on the Sustainable Development Goals, The Gender Snapshot 2019. New York, USA: UN Women; $2019 . \quad$ Retrieved from: https://oig.cepal.org/en/documents/progress-sustainable-development-goals-gender-snapshot-2019

Van Hoof, E. (2020). Lockdown is the world's biggest psychological experiment - and we will pay the price. World Economic Forum. Retrieved from https://www.weforum.org/agenda/2020/04/this-is-the-psychological-side-of-the-covid-19-pandemic-that-were-igno ring/

Veenhoven, R. (2008). Healthy happiness: Effects of happiness on physical health and the consequences for preventive health care. Journal of happiness studies, 9(3), 449-469.

Wang, C., Pan, R., Wan, X., Tan, Y., Xu, L., Ho, C. S., \& Ho, R. C. (2020). Immediate psychological responses and associated factors during the initial stage of the 2019 coronavirus disease (COVID-19) epidemic among the general population in China. International journal of environmental research and public health, 17(5), 1729. https://doi.org/10.3390/ijerph17051729

Wang, C., Pan, R., Wan, X., Tan, Y., Xu, L., McIntyre, R. S., ... \& Ho, C. (2020). A longitudinal study on the mental health of general population during the COVID-19 epidemic in China. Brain, behavior, and immunity, 87, 40-48.

World Bank. COVID-19 Could Worsen Gender Inequality in Latin America and the Caribbean. https://www.worldbank.org/en/news/feature/2020/05/15/covid-19-could-worsen-gender-inequality-in-latin-america -and-the-caribbean . Published May $15^{\text {th }}, 2020$. Accessed July $17^{\text {th }}, 2020$.

Zandifar, A., \& Badrfam, R. (2020). Iranian mental health during the COVID-19 epidemic. Asian journal of psychiatry, 51. https://doi.org/10.1016/j.ajp.2020.101990

Zhai, Y., \& Du, X. (2020). Addressing collegiate mental health amid COVID-19 pandemic. In Psychiatry Research. https://doi.org/10.1016/j.psychres.2020.113003

\section{Copyrights}

Copyright for this article is retained by the author(s), with first publication rights granted to the journal.

This is an open-access article distributed under the terms and conditions of the Creative Commons Attribution license (http://creativecommons.org/licenses/by/4.0/). 